\title{
Immunoregulation of bovine macrophages by factors in the salivary glands of Rhipicephalus microplus
}

\author{
Danett K Brake* and Adalberto A Pérez de León
}

\begin{abstract}
Background: Alternative strategies are required to control the southern cattle tick, Rhipicephalus microplus, due to evolving resistance to commercially available acaricides. This invasive ectoparasite is a vector of economically important diseases of cattle such as bovine babesiosis and anaplasmosis. An understanding of the biological intricacies underlying vector-host-pathogen interactions is required to innovate sustainable tick management strategies that can ultimately mitigate the impact of animal and zoonotic tick-borne diseases. Tick saliva contains molecules evolved to impair host innate and adaptive immune responses, which facilitates blood feeding and pathogen transmission. Antigen presenting cells are central to the development of robust $T$ cell responses including Th1 and Th2 determination. In this study we examined changes in co-stimulatory molecule expression and cytokine response of bovine macrophages exposed to salivary gland extracts (SGE) obtained from 2-3 day fed, pathogen-free adult $R$. microplus.

Methods: Peripheral blood-derived macrophages were treated for $1 \mathrm{hr}$ with 1,5 , or $10 \mu \mathrm{g} / \mathrm{mL}$ of SGE followed by $1,6,24 \mathrm{hr}$ of $1 \mu \mathrm{g} / \mathrm{mL}$ of lipopolysaccharide (LPS). Real-time PCR and cytokine ELISA were used to measure changes in co-stimulatory molecule expression and cytokine response.

Results: Changes were observed in co-stimulatory molecule expression of bovine macrophages in response to $R$. microplus SGE exposure. After 6 hrs, CD86, but not CD80, was preferentially up-regulated on bovine macrophages when treated with $1 \mu \mathrm{g} / \mathrm{ml} \mathrm{SGE}$ and then LPS, but not SGE alone. At 24 hrs CD80, CD86, and CD69 expression was increased with LPS, but was inhibited by the addition of SGE. SGE also inhibited LPS induced upregulation of TNF $\alpha$, IFN $\gamma$ and IL-12 cytokines, but did not alter IL-4 or CD40 mRNA expression.

Conclusions: Molecules from the salivary glands of adult R. microplus showed bimodal concentration-, and timedependent effects on differential up-regulation of CD86 in bovine macrophages activated by the TLR4-ligand, LPS. Up regulation of proinflammatory cytokines and IL-12, a Th1 promoting cytokine, were inhibited in a dosedependent manner. The co-stimulatory molecules CD80, as well as the cell activation marker, CD69, were also suppressed in macrophages exposed to SGE. Continued investigation of the immunomodulatory factors will provide the knowledge base to research and develop therapeutic or prophylactic interventions targeting $R$. microplus-cattle interactions at the blood-feeding interface.
\end{abstract}

\section{Background}

Ticks are external parasitic organisms that have to overcome host defence mechanisms to obtain blood for their survival. They also serve as vectors of pathogens causing important diseases in animals and humans [1]. As a

\footnotetext{
* Correspondence: danett.brake@ars.usda.gov

USDA-ARS Knipling-Bushland U.S. Livestock Insects Research Laboratory, 2700 Fredericksberg Rd, Kerrville, TX 78028 USA
}

result, complex tick-pathogen-host interactions have developed through evolutionary time. The southern cattle tick, Rhipicephalus (Boophilus) microplus, is one of the most economically important parasites of livestock. Additionally, this invasive tick species is also a significant vector of Babesia bigemina and B. bovis that cause bovine babesiosis, which can be deadly to cattle [2]. Alternative strategies are required to control R. microplus as populations across the globe continue to evolve

\section{Biomed Central}

(C) 2012 Brake and Pérez de León; licensee BioMed Central Ltd. This is an Open Access article distributed under the terms of the Creative Commons Attribution License (http://creativecommons.org/licenses/by/2.0), which permits unrestricted use, distribution, and reproduction in any medium, provided the original work is properly cited. 
resistance to commercially available acaricides [3,4]. An understanding of the biological intricacies underlying vector-host-pathogen interactions, including those involving the host immune system, is required to innovate sustainable tick management strategies that can ultimately mitigate the impact of animal and zoonotic tickborne diseases.

Tissue injury at the tick feeding site activates the different arms of the host immune system. While feeding, ticks secrete bioactive salivary factors to modulate humoral and cellular components of the innate and acquired immune responses to improve reproductive fitness $[5,6]$. This immunomodulation by salivary factors has been shown to affect the activity of antigen presenting cells (APC's), lymphocytes and other cells, and to inhibit complement activation [7-11]. These effects on the host immune system may also enhance the transmission of tick-borne pathogens [5].

Many types of APC's including macrophages, different subtypes of dendritic cells (DC), and natural killer (NK) cells reside in the skin and play a crucial role in inducing protective $\mathrm{T}$ cell responses. Langerhans cells (LC), a type of DC found in the skin, from guinea pig epidermis have been shown to acquire antigens from tick salivary glands, migrate from infestation sites and present them at local lymph nodes $[12,13]$. Tick-sensitized animals have greater numbers of LC at sites of tick infestation [14].

How tick saliva alters antigen presenting cell function is not well understood. Inflammatory signals can effect DC homeostasis, activation and differentiation [15]. Several studies describe the effects of saliva, or salivary gland extracts (SGE) on proinflammatory cytokine expression in murine in vitro models. Studies with Dermacentor andersoni, Ixodes pacificus, I. ricinus, and $R$. sanguineus have shown a tick-induced shift away from Th1 cytokines such as tumor necrosis factor $\alpha$ (TNF $\alpha)$, interferon $\gamma$ (IFN $\gamma$ ), and interleukin $1 \beta$ (IL-1 $\beta$ ), to promoting up-regulation of interlukin-10 (IL-10), and interlukin-4 (IL-4), which are consistent with Th2 polarization [11,16-21]. Specifically, a sphinomyelinaselike enzyme has been identified in I. scapularis that reduces antigen specific responses and promotes Th2 polarization $[18,22]$.

Tick saliva may direct DC differentiation and function to drive naïve CD4 $\mathrm{T}$ cells towards Th2 differentiation [16,23]. Mice deficient in Langerhans cells, a subset of skin DCs, prevent the suppression of a Th1 response when exposed to I. scapularis ticks [24]. Salivary prostaglandin $\mathrm{E}_{2}$ from $I$. scapularis can also suppress $\mathrm{CD} 4 \mathrm{~T}$ cell proliferation by in vitro derived dendritic cells [25]. Altering the host immune response to a Th2 phenotype may benefit the transmission by $R$. microplus of pathogens like the apicomplexan protozoa causing bovine babesiosis, which would be more successfully controlled by a Th1 response [26].

Another possible route to suppress APC's ability to induce a robust $\mathrm{T}$ cell response is by inhibiting cell maturation and activation. Upon activation, APCs upregulate $\mathrm{CD} 80$ and $\mathrm{CD} 86$, which via binding to $\mathrm{CD} 28$ provide co-stimulatory signals for $\mathrm{T}$ cell activation [27]. CD80 and CD86 can modulate naïve T cells towards Th1 or Th2 pathways [28-30]. While CD80 preferentially favors Th1 type $\mathrm{T}$ cell differentiation, CD86 promotes IL-4 production and Th2 T cell differentiation [29,31,32]. CD86 can be differentially regulated by various cytokines including the Th2 cytokine, IL-4 [33]. Using a murine macrophage cell line, we demonstrated that molecules in $\mathrm{SGE}$ of $R$. microplus have a concentration-dependent effect on differential up-regulation of CD86 by the TLR4 ligand, LPS [34]. This CD86 up-regulation is at least partially dependent on the ERK $1 / 2$ pathway, and may serve to promote Th2 polarization of the immune response. Here, we investigated the effects of $R$. microplus salivary gland extract (SGE) on co-stimulatory molecule expression, macrophage activation, and cytokine expression in cultured bovine macrophages.

\section{Methods}

\section{Isolation of Tick Salivary Glands}

The R. microplus Deutch strain used as the source of ticks for this study originated from samples collected in Webb County, TX during an outbreak in 2001. The Deutch strain has been maintained by standard rearing practices at the USDA-ARS Cattle Fever Tick Research Laboratory at Moore Field, TX. The ticks were determined free of Babesia bovis and Babesia bigemina as described previously [35] and SGE was isolated as previously described [34]. Larvae were placed in patches and allowed to feed following protocols approved by the Institutional Animal Care and Use Committee of the USDA-ARS KniplingBushland Livestock Insects Research Laboratory. Adult ticks were fed for 2-3 days, cleaned with 70\% ethanol and dissected. Salivary glands were sonicated at $55 \mathrm{kHz}$ for three 20 second pulses on ice in Dulbecco's phosphate buffered saline (PBS) (Sigma, St. Louis, MO) and centrifuged at $14,000 \times \mathrm{g}$ for 20 minutes at $4^{\circ} \mathrm{C}$. The supernatant was collected and protein concentration was determined by Pierce BCA (bicinchoninic acid) Protein Assay (Thermo Scientific, Rockford, IL). The SGE was aliquoted and subsequently frozen at $-70^{\circ} \mathrm{C}$.

\section{Isolation and culture of bovine macrophages}

Whole blood was drawn from healthy Hereford cows following protocols approved by the Institutional Animal Care and Use Committee of the USDA-ARS KniplingBushland Livestock Insects Research Laboratory. Peripheral blood mononuclear cells (PBMC's) were isolated by 
whole blood centrifugation using histopaque-1077 (Sigma-Aldrich, St. Louis, MO). PBMC's were seeded onto 24-well tissue culture treated plates in serum free RPMI 1640 (Gibco-Invitrogen, Carlsbad, CA). Monocytes were allowed to attach for $3 \mathrm{hrs}$ at $37^{\circ} \mathrm{C}$. Nonadherent cells were removed by serial washes with Dulbecco's phosphate-buffered saline (PBS) (Sigma, St. Louis, MO). Antibiotic-free RPMI media supplemented with $10 \%$ heat inactivated FBS was exchanged every 3-4 days. After 8-10 days, > 95\% of cells had morphological characteristics consistent with a macrophage phenotype.

\section{Real-time Quantitative PCR}

Bovine in vitro differentiated macrophages were treated for $1 \mathrm{hr}$ with $0,1,5$ or $10 \mu \mathrm{g} / \mathrm{mL}$ of SGE followed by $1 \mu \mathrm{g} / \mathrm{mL}$ LPS or no additional treatment. After 1, 6 or 24 hrs of LPS treatment total RNA was extracted by spin column centrifugation using the RNAeasy Mini Kit (Qiagen, Valencia, CA). RNA concentration and absorbance at $260 / 280 \mathrm{~nm}$ was determined using a NanoDrop spectrophotometer (Thermo Scientific, Wilmington, DE) and RNA quality was analysed by non-denaturing agarose gel electrophoresis. cDNA synthesis and real-time PCR was performed as previously described [34]. For the amplification of specific mRNA, pre-inventoried 20× TaqMan MGB probe-primer sets for bovine TNF and GAPDH were purchased (Applied Biosystems, Foster City, CA). For other bovine genes, custom probe-primer sets were designed as shown on Table 1 (Sigma-Aldrich, St. Louis, MO). PCR was performed in a CFX96 Real-Time PCR Detection System (BioRad, Hercules, CA). Reactions were performed in duplicate. Relative mRNA expression was calculated by comparative $C_{\mathrm{t}^{-}}$ method [36]. GAPDH was used as the endogenous control.

\section{ELISA}

Bovine in vitro differentiated macrophages were treated for $1 \mathrm{hr}$ with $0,1,5$ or $10 \mu \mathrm{g} / \mathrm{mL}$ of SGE followed by 1 $\mu \mathrm{g} / \mathrm{mL}$ LPS for 24 hours. Cell culture supernatant was collected and quantities of TNF $\alpha$ and IFN- $\gamma$ were assessed using bovine ELISA kits (R\&D Systems,
Minneapolis, MN). Briefly, undiluted supernatant was incubated in the ELISA plate for 2 hrs, followed by washing and incubation with secondary reagents as supplied. Plates were read using a Spectramax Plus Microplate Spectrophotometer and Softmax Pro analysis software (Molecular Devices, Sunnyvale, CA).

\section{Statistics}

Results of 3-4 independent experiments are expressed as means \pm SE. Significant differences between means were determined using unpaired Student's t-tests, or two-way analysis of variance (ANOVA) with $\mathrm{P}<0.05$ considered statistically significant.

\section{Results}

\section{Changes in co-stimulatory molecule expression induced} by SGE

Co-stimulatory molecule mRNA profiles of in vitro differentiated bovine macrophages were assayed by quantitative real-time PCR after 1,6 , or 24 hrs of treatment with or without 1,5 , or $10 \mu \mathrm{g} / \mathrm{mL}$ of SGE from adult ticks fed on cattle for 3 days, and $1 \mu \mathrm{g} / \mathrm{mL}$ of LPS. CD80, CD86, CD40 and CD69 were up-regulated in the presence of LPS (Figure 1). SGE alone did not alter message expression compared to untreated control at any concentration tested. $5 \mu \mathrm{g} / \mathrm{mL}$ SGE alone is represented in Figures 1 \&2. The $1 \mathrm{hr}$ pre-treatment of SGE did reduce LPS induced up-regulation of CD80 and CD69 message in a dose dependent fashion $(\mathrm{P} \leq 0.05)$; however, CD40 expression was not significantly changed. Bovine macrophages treated with $1 \mu \mathrm{g} / \mathrm{mL}$ SGE and LPS showed increased CD86 expression at $6 \mathrm{hrs}$ as compared to LPS alone, SGE alone or untreated cells. All concentrations of SGE treatments with LPS showed decreased CD86 expression after $24 \mathrm{hrs}$ as compared to LPS alone.

\section{Changes in cytokine expression following exposure to SGE}

Cytokine mRNA expression levels were measured at 1, 6 and $24 \mathrm{hrs}$ after LPS stimulation in the presence or

Table 1 Genes analysed by Taqman quantitative real-time PCR

\begin{tabular}{lllll}
\hline Gene name & NCBI Accession & Sense & Anti-sense & Probe: FAM-TAMRA \\
\hline CD86 & NM_001038017 & TAAGGCCGACAGCAGTTTCC & TCACCCCGTTATTAAGATGATAGC & TCCCAGCTCTGCTTCCAGTCGGGT \\
\hline CD40 & Y09950 & GCATTGTGATCCTGGCTCTG & CTGATCATTAACCTCACGGAAGTC & TGTCGGACAGTGGCACCTACACCT \\
\hline CD69 & NM_174014 & ACCTTGGCCCAAAACTTTGC & CAGCCCGATCCAGTGTTCAG & AACATGGTGCCACGCTTGCTGTCA \\
\hline IFN- $\gamma$ & NM_174086 & GAAAGCGGAAGAGAAGTCAGAATC & CAAATATTGCAGGCAGGAGGAC & ACGTTGATGCTCTCCGGCCTCGAA \\
\hline IL-12p40 & NM_174356 & TGTGACACTCCTGAAGAAGATGG & CCAAACTCTTTGACTTGGATGGTC & TGCCAGAGCCCAAGACCTCACTGC \\
\hline IL-10 & NM_174088 & CTCTGTTGCCTGGTCTTCCTG & TGGTTGGCAAGTGGATACAGC & CAGCCAGCCGAGATGCGAGCACC \\
\hline IL-4 & NM_173921 & AGCAAGACCTGTTCTGTGAATG & CAGCTTCAACACTTGGAGTATTC & AGCCAAGACGAGCACAAGTACGCT \\
\hline
\end{tabular}

Gene names, NCBI gene accession, sense and anti-sense primer sequences ( $5^{\prime}$ to $\left.3^{\prime}\right)$ and Taqman probe sequence. 


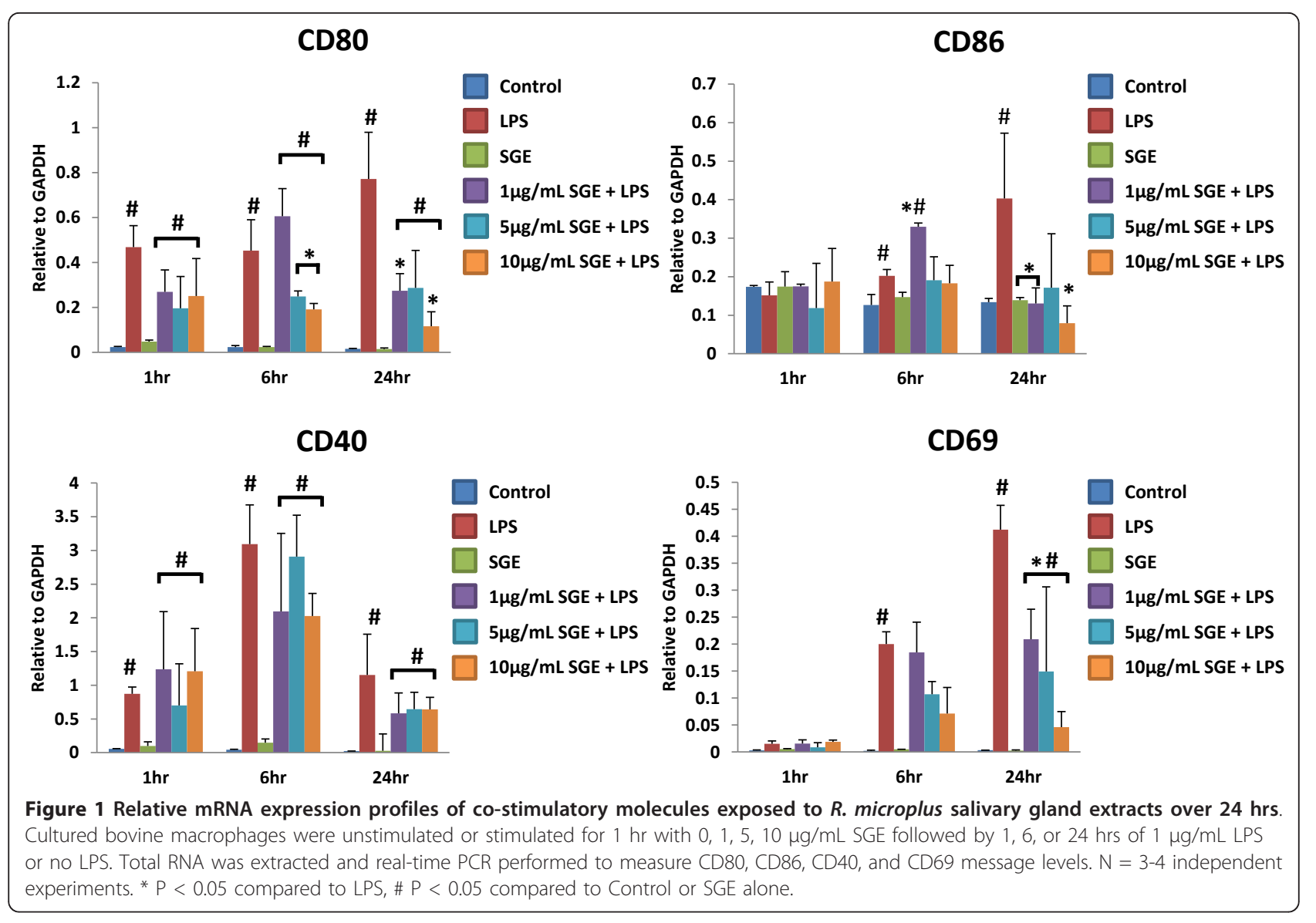

absence of varying SGE concentrations (Figure 2). No significant differences in IL-4 message were detected with SGE alone, LPS alone, and LPS in combination with SGE at any concentration tested. However, TNF, IFN- $\gamma$, and IL-12 mRNA expression was significantly decreased in LPS with SGE groups in a dose-dependent fashion when compared to LPS alone, SGE alone, or unstimulated control cells. Protein expression of TNF $\alpha$ and IFN- $\gamma$ were measured in cell supernatant after 24 hrs of LPS stimulation (Figure 3). TNF $\alpha$ and IFN- $\gamma$ were not detected in the control group, or the groups exposed to 1,5 , and $10 \mu \mathrm{g} / \mathrm{mL}$ SGE without LPS stimulation. A dose-dependent decrease of cytokine expression was observed with the addition of SGE when stimulated with LPS. Taken together, these data indicate $R$. microplus SGE contains factor(s) that supress LPSinduced stimulation of macrophage activation, and cytokine responses.

\section{Discussion}

Cattle infested with $R$. microplus have been shown to reduce circulating bovine $\mathrm{T}$ and $\mathrm{B}$ cell numbers, and decreased cell responsiveness [37]. By comparison to innately resistant $B$. indicus cattle, less resistant $B$. taurus breeds showed reduced numbers of basophils and eosinophils. Bovine microarray studies have shown that $R$. microplus differentially alters gene expression in susceptible B. taurus cattle as compared to Bos indicus breeds [38,39]. The expression of hemostatic proteins and adhesion molecules controlling coagulation and the recruitment of immune cells into sites of infestation, respectively, was also altered $[40,41]$.

This study expands our investigations documenting how SGE from adult $R$. microplus affects the host's ability to mount a successful immune response by altering co-stimulatory and activation marker expression of bovine macrophages in vitro. Similar to our previous report using a mouse macrophage cell line [34], bovine macrophage CD40, which binds CD40L on T cells, was not significantly affected by exposure to SGE. At relatively low physiologic concentrations of SGE, as observed in our previous report, CD86 is up-regulated after 6 hours of LPS stimulation, but this effect was not seen at higher SGE concentrations. This finding is consistent with concentration-dependent bi-modal responses to differing levels of exposure to tick salivary proteins in the skin microenvironment and systemic responses. Low to moderate infestations with $R$. 


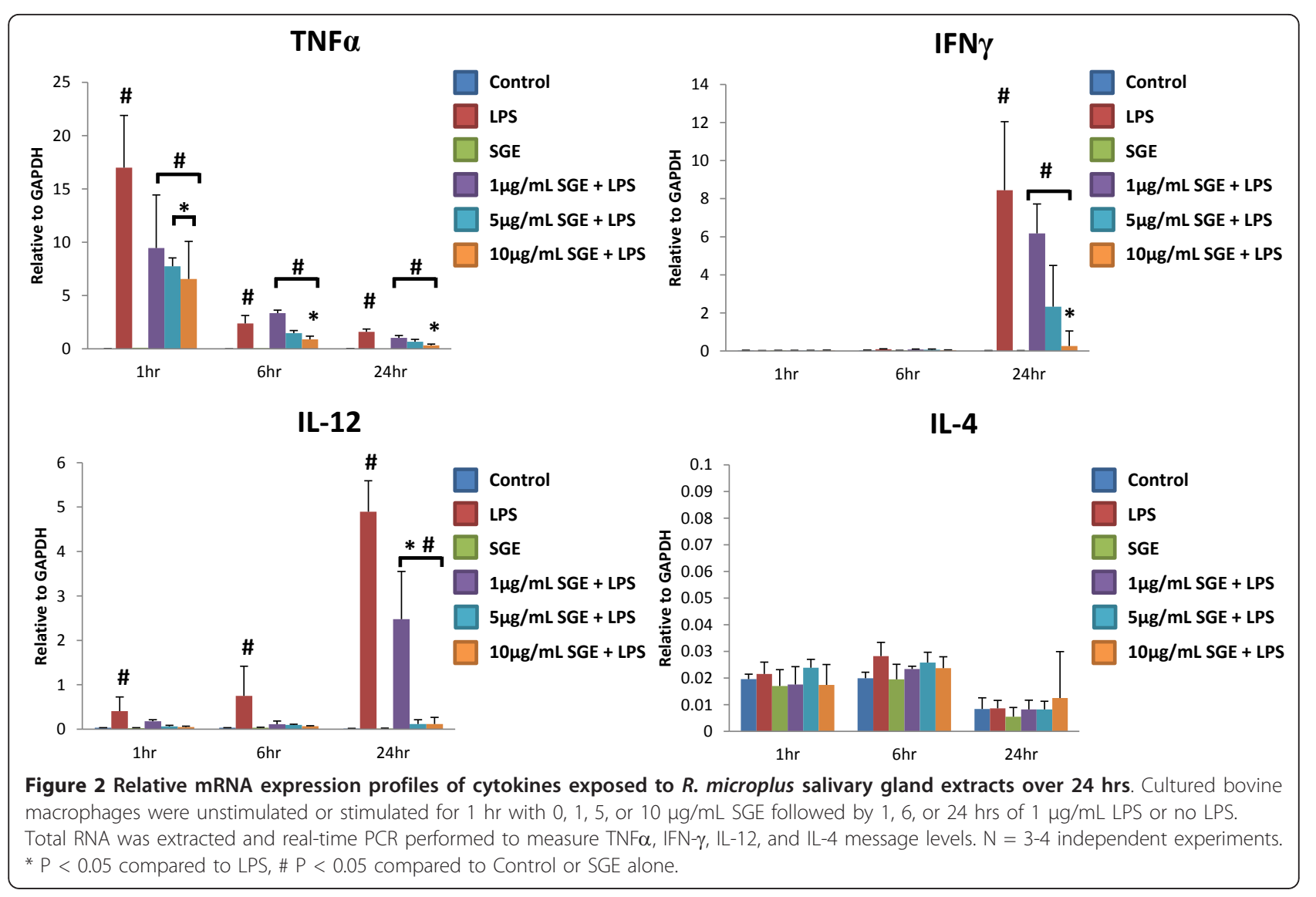

microplus has been shown to induce an IgE response in cattle, whereas high infestations show increases in IgG antibody production [42]. CD86 expressed on human B cells can also promote IgE production when stimulated with IL-4 [43].
In contrast to results obtained with murine RAW 264.7 cells, in vitro differentiated bovine macrophages demonstrated a dramatic decrease in CD80 and CD86 mRNA expression by 24 hours of exposure to 5 and 10 $\mu \mathrm{g} / \mathrm{mL}$ of SGE in the presence of LPS. These divergent

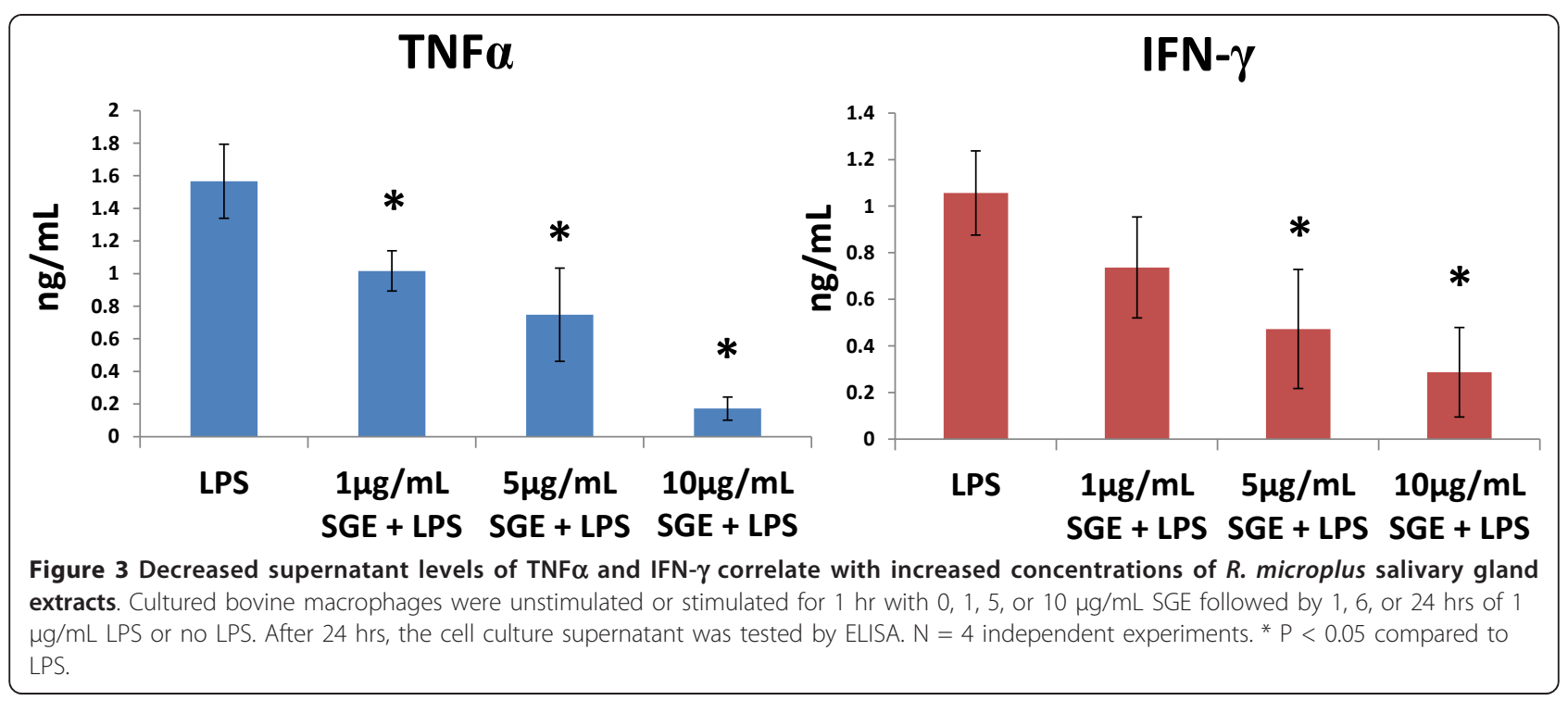


results highlight the differences in response between murine and bovine systems. Higher concentrations of saliva from adult $R$. sanguineus females fed for seven days can inhibit differentiation and maturation of murine bone-marrow-derived dendritic cells including CD80 and CD86 expression [23]. I. ricinus saliva pulsed dendritic cells were first reported to drive a Th2 response using $15 \mu \mathrm{g} / \mathrm{mL}$ saliva from females fed for 5.5 days $[16,17]$. In the presence of IL-1 $\beta$, these DCs showed increased CD80 and CD86 expression and increased IL4 production leading to Th2 priming of naïve CD4 T cells. Prostaglandin $\mathrm{E}_{2}$ from $I$. scapularis saliva was shown to increase CD86 expression of LPS stimulated murine bone-marrow derived DC, while it inhibited IL12 p70 and TNF $\alpha$ protein expression in culture supernatants [25]. We did not observe changes in IL-4, but TNF $\alpha$, IL-12p40, IFN- $\gamma$, CD80 and CD86 mRNA expression were decreased following exposure to $R$. microplus SGE at concentrations $\leq 10 \mu \mathrm{g} / \mathrm{mL}$. These findings could be explained by differing immunoregulatory proteomes among species, varying concentration of salivary components tested, as well as changing compositions of salivary gland protein profiles during blood feeding [11,44-46].

These data support the hypothesis that in addition to altering APC function, the overall maturation and activation may be actively suppressed by molecules present in salivary glands of $R$. microplus. During the process of maturation macrophages and immature DCs change from phagocytic antigen processors to highly efficient activators of T cells. Up-regulation of CD80 and CD86 are markers of cell maturation as well as CD69. CD69 is expressed following activation in all bone marrowderived cells [47]. The role of CD69 in the activation and regulation of the bovine immune response to tick salivary molecules is unknown. Our results document that CD69 expression is significantly reduced when SGE is present prior to LPS activation. Thus, tick salivary factors may actively prevent APC maturation needed for proper T cell activation. Additionally, CD69 is a complex co-stimulatory and immunoregulatory molecule as reviewed in [48]. CD69 may act as a proinflammatory receptor, promoting TNF $\alpha$, nitric oxide secretion and IL-2 production, which increase $\mathrm{T}$-cell proliferation. Knockout of CD69 in a murine asthma model showed increased eosinophil recruitment and enhanced Th2 cytokines in lung tissue [49]. Therefore CD69 may play a role in limiting Th2 responses. Further studies are needed to elucidate the role of CD69 in tick immunoregulation of host responses.

In adult $B$. taurus, ticks modulate host immune responses away from a Th1 profile by decreasing IFN $\gamma$, while promoting a Th2 phenotype via increased IL-4 production $[18,19,23]$. Moreover, this Th2 response appears to facilitate pathogen transmission [50,51]. By comparison, young calves demonstrate a strong innate immunity to $B$. bovis that has been characterized as a Th1 response with macrophage induction of IL-12 and early IFN- $\gamma$ response by NK cells [52,53]. Increasing evidence points to the central importance of macrophages, DCs and NK cells in the spleen-dependent immune response of calves to $B$. bovis [54,55]. IL-12 produced by $B$. bovis exposed monocytes was sufficient to drive IFN$\gamma$ production by NK cells [56]. Evidence of crosstalk between human DCs and NK cells has revealed that DCs can improve the effector function of NK cells and in response NK cells can promote maturation and immunostimulatory properties of DCs [57]. This interaction may be a likely target for immunosuppression by tick salivary factors. $R$. sanguineus has been shown to suppress IL-12 production in murine bone-marrow derived DCs after LPS stimulation [23]. To the best of the authors' knowledge, this report is the first to document that $R$. microplus salivary gland proteins reduce IL-12 message in bovine macrophages activated by LPS. Reduced IL-12 is consistent with lower levels of IFN- $\gamma$ and TNF $\alpha$, which correlate with the suppression of a Th1 response. These studies are limited to largely looking at changes in mRNA message profiles, and have not been correlated to protein levels. Additional studies are warranted to identify and characterize the immunomodulatory factors in the salivary glands of $R$. microplus and investigate the molecular mechanisms affecting bovine APCs. Examining the downstream effects on $\mathrm{T}$ cell memory and effector function, NK activation and crosstalk in cattle will contribute to our understanding of how components in tick saliva suppress Th1 responses. Knowledge of the immunobiological intricacies underlying the tick-host blood feeding interface offers the opportunity to innovate sustainable technologies to mitigate the impact of $R$. microplus on livestock production systems globally.

\section{Conclusions}

Molecules in the salivary glands of adult $R$. microplus showed bimodal concentration-, and time-dependent effects on differential up-regulation of CD86 in bovine macrophages activated by the TLR4-ligand, LPS. Proinflammatory cytokines and the Th1 promoting cytokine, IL-12, were down regulated in a dose-dependent manner. The co-stimulatory molecule CD80 and the activation marker CD69 were also suppressed by salivary gland extracts. Our results indicate that salivary gland factors may prevent activation of the innate immune system in parasitized cattle. Further studies to identify and characterize the immunomodulatory salivary factors secreted by $R$. microplus at the feeding site are warranted to assess their molecular mechanism, and to test 
the hypothesis that they are involved in the transmission of Babesia spp.

\section{Acknowledgements}

Mention of trade names or commercial products in this publication is solely for the purpose of providing specific information and does not imply recommendation or endorsement by the U.S. Department of Agriculture. Our appreciation goes to Jason Tidwell for technical assistance, Keith Shelley and Larry Camarillo for animal care and sample acquisition. This study was financially supported by USDA-ARS appropriated project 6205-32000-03100D. The USDA is an equal opportunity provider and employer.

\section{Authors' contributions}

DKB conceived, designed and performed the experiments. Manuscript was primarily written by DKB with review of the manuscript provided from AAPL. AAPL conceived, administered, and supervised funding for the experiments. All authors read and approved the final manuscript.

\section{Competing interests}

The authors declare that they have no competing interests.

Received: 28 September 2011 Accepted: 14 February 2012 Published: 14 February 2012

\section{References}

1. Jongejan F, Uilenberg G: The global importance of ticks. Parasitology 2004, 129(Suppl):S3-14.

2. Bock $R$, Jackson $L$, de Vos A, Jorgensen W: Babesiosis of cattle. Parasitology 2004, 129(Suppl):S247-269.

3. Miller RJ, Davey RB, George JE: First report of permethrin-resistant Boophilus microplus (Acari: Ixodidae) collected within the United States. J Med Entomol 2007, 44:308-315.

4. Fernandez-Salas A, Rodriguez-Vivas Rl, Alonso-Diaz MA: First report of a Rhipicephalus microplus tick population multi-resistant to acaricides and ivermectin in the Mexican tropics. Vet Parasitol 2011, 172:109-113.

5. Wikel SK: Tick modulation of host immunity: an important factor in pathogen transmission. Int J Parasitol 1999, 29:851-859.

6. Fontaine A, Diouf I, Bakkali N, Misse D, Pages F, Fusai T, Rogier C, Almeras L: Implication of haematophagous arthropod salivary proteins in hostvector interactions. Parasit Vectors 2011, 4:187.

7. Maruyama SR, Anatriello E, Anderson JM, Ribeiro JM, Brandao LG, Valenzuela JG, Ferreira BR, Garcia GR, Szabo MP, Patel S, et al: The expression of genes coding for distinct types of glycine-rich proteins varies according to the biology of three metastriate ticks, Rhipicephalus (Boophilus) microplus, Rhipicephalus sanguineus and Amblyomma cajennense. BMC Genomics 2010, 11:363.

8. Murrell A, Barker SC: Synonymy of Boophilus Curtice, 1891 with Rhipicephalus Koch, 1844 (Acari: Ixodidae). Syst Parasitol 2003, 56:169-172.

9. Jonsson NN, Bock RE, Jorgensen WK: Productivity and health effects of anaplasmosis and babesiosis on Bos indicus cattle and their crosses, and the effects of differing intensity of tick control in Australia. Vet Parasitol 2008, 155:1-9.

10. Steen NA, Barker SC, Alewood PF: Proteins in the saliva of the Ixodida (ticks): pharmacological features and biological significance. Toxicon 2006, 47:1-20.

11. Brossard M, Wikel SK: Tick immunobiology. Parasitology 2004, 129(Suppl): S161-176.

12. Allen JR, Khalil HM, Wikel SK: Langerhans cells trap tick salivary gland antigens in tick-resistant guinea pigs. J Immunol 1979, 122:563-565.

13. Nithiuthai S, Allen JR: Langerhans cells present tick antigens to lymph node cells from tick-sensitized guinea-pigs. Immunology 1985, 55:157-163.

14. Nithiuthai S, Allen JR: Significant changes in epidermal Langerhans cells of guinea-pigs infested with ticks (Dermacentor andersoni). Immunology 1984, 51:133-141.

15. Merad M, Ginhoux F: Dendritic cell genealogy: a new stem or just another branch? Nat Immunol 2007, 8:1199-1201.

16. Mejri N, Brossard M: Splenic dendritic cells pulsed with Ixodes ricinus tick saliva prime naive CD4+T to induce Th2 cell differentiation in vitro and in vivo. Int Immunol 2007, 19:535-543.
17. Mejri N, Franscini N, Rutti B, Brossard M: Th2 polarization of the immune response of $B A L B / C$ mice to Ixodes ricinus instars, importance of several antigens in activation of specific Th2 subpopulations. Parasite Immunol 2001, 23:61-69.

18. Muller-Doblies UU, Maxwell SS, Boppana VD, Mihalyo MA, McSorley SJ, Vella AT, Adler AJ, Wikel SK: Feeding by the tick, Ixodes scapularis, causes CD4(+) T cells responding to cognate antigen to develop the capacity to express IL-4. Parasite Immunol 2007, 29:485-499.

19. Schoeler GB, Manweiler SA, Wikel SK: Cytokine responses of $\mathrm{C} 3 \mathrm{H} / \mathrm{HeN}$ mice infested with Ixodes scapularis or Ixodes pacificus nymphs. Parasite Immunol 2000, 22:31-40.

20. Ferreira BR, Silva JS: Successive tick infestations selectively promote a Thelper 2 cytokine profile in mice. Immunology 1999, 96:434-439.

21. Macaluso KR, Wikel SK: Dermacentor andersoni: effects of repeated infestations on lymphocyte proliferation, cytokine production, and adhesion-molecule expression by BALB/c mice. Ann Trop Med Parasitol 2001, 95:413-427.

22. Boppana VD, Thangamani S, Alarcon-Chaidez FJ, Adler AJ, Wikel SK: Blood feeding by the Rocky Mountain spotted fever vector, Dermacentor andersoni, induces interleukin-4 expression by cognate antigen responding CD4+ T cells. Parasit Vectors 2009, 2:47.

23. Cavassani KA, Aliberti JC, Dias AR, Silva JS, Ferreira BR: Tick saliva inhibits differentiation, maturation and function of murine bone-marrow-derived dendritic cells. Immunology 2005, 114:235-245

24. Vesely DL, Fish D, Shlomchik MJ, Kaplan DH, Bockenstedt LK: Langerhans cell deficiency impairs Ixodes scapularis suppression of Th1 responses in mice. Infect Immun 2009, 77:1881-1887.

25. Sa-Nunes A, Bafica A, Lucas DA, Conrads TP, Veenstra TD, Andersen JF, Mather TN, Ribeiro JM, Francischetti IM: Prostaglandin E2 is a major inhibitor of dendritic cell maturation and function in Ixodes scapularis saliva. J Immunol 2007, 179:1497-1505.

26. Hajnicka V, Vancova I, Kocakova P, Slovak M, Gasperik J, Slavikova M, Hails RS, Labuda M, Nuttall PA: Manipulation of host cytokine network by ticks: a potential gateway for pathogen transmission. Parasitology 2005, 130:333-342.

27. Sharpe AH, Freeman GJ: The B7-CD28 superfamily. Nat Rev Immunol 2002, 2:116-126.

28. Chen $X Q$, Yang J, Hu SP, Nie HX, Mao GY, Chen HB: Increased expression of CD86 and reduced production of IL-12 and IL-10 by monocytederived dendritic cells from allergic asthmatics and their effects on Th1and Th2-type cytokine balance. Respiration 2006, 73:34-40.

29. Ranger AM, Das MP, Kuchroo VK, Glimcher LH: B7-2 (CD86) is essential for the development of IL-4-producing T cells. Int Immunol 1996, 8:1549-1560

30. Yoshida T, Hachimura S, Ishimori M, Ise W, Totsuka M, Ametani A, Kaminogawa S: Interleukin 12 and CD86 Regulate Th1 and Th2 Development Induced by a Range of Antigen Doses Presented by Peyer's Patch and Spleen Cells. Cytotechnology 2003, 43:81-88.

31. Brown JA, Titus RG, Nabavi N, Glimcher LH: Blockade of CD86 ameliorates Leishmania major infection by down-regulating the Th2 response. J Infect Dis 1996, 174:1303-1308.

32. Wang Z, Takamoto M, Sugane $K$ : Costimulatory signal through CD86 is important in Th2 response in Trichinella spiralis infected mice. Parasite Immunol 2000, 22:121-130.

33. Deszo EL, Brake DK, Kelley KW, Freund GG: IL-4-dependent CD86 expression requires JAK/STAT6 activation and is negatively regulated by PKCdelta. Cell Signal 2004, 16:271-280.

34. Brake DK, Wikel SK, Tidwell JP, Perez de Leon AA: Rhipicephalus microplus salivary gland molecules induce differential CD86 expression in murine macrophages. Parasit Vectors 2010, 3:103.

35. Guerrero FD, Bendele KG, Davey RB, George JE: Detection of Babesia bigemina infection in strains of Rhipicephalus (Boophilus) microplus collected from outbreaks in south Texas. Vet Parasitol 2007, 145:156-163.

36. Raaijmakers MH, van Emst L, de Witte T, Mensink E, Raymakers RA: Quantitative assessment of gene expression in highly purified hematopoietic cells using real-time reverse transcriptase polymerase chain reaction. Exp Hematol 2002, 30:481-487.

37. Inokuma $H$, Kerlin RL, Kemp DH, Willadsen P: Effects of cattle tick (Boophilus microplus) infestation on the bovine immune system. Vet Parasitol 1993, 47:107-118. 
38. Piper EK, Jackson LA, Bagnall NH, Kongsuwan KK, Lew AE, Jonsson NN: Gene expression in the skin of Bos taurus and Bos indicus cattle infested with the cattle tick, Rhipicephalus (Boophilus) microplus. Vet Immunol Immunopathol 2008, 126:110-119.

39. Piper EK, Jonsson NN, Gondro C, Lew-Tabor AE, Moolhuijzen P, Vance ME, Jackson LA: Immunological profiles of Bos taurus and Bos indicus cattle infested with the cattle tick, Rhipicephalus (Boophilus) microplus. Clin Vaccine Immunol 2009, 16:1074-1086.

40. Carvalho WA, Franzin AM, Abatepaulo AR, de Oliveira CJ, More DD, da Silva JS, Ferreira BR, de Miranda Santos IK: Modulation of cutaneous inflammation induced by ticks in contrasting phenotypes of infestation in bovines. Vet Parasitol 2010, 167:260-273.

41. Carvalho WA, Maruyama SR, Franzin AM, Abatepaulo AR, Anderson JM, Ferreira BR, Ribeiro JM, More DD, Augusto Mendes Maia A, Valenzuela JG, et al: Rhipicephalus (Boophilus) microplus: clotting time in tick-infested skin varies according to local inflammation and gene expression patterns in tick salivary glands. Exp Parasitol 2010, 124:428-435.

42. Kashino SS, Resende J, Sacco AM, Rocha C, Proenca L, Carvalho WA Firmino AA, Queiroz R, Benavides M, Gershwin LJ, De Miranda Santos IK: Boophilus microplus: the pattern of bovine immunoglobulin isotype responses to high and low tick infestations. Exp Parasitol 2005, 110:12-21.

43. Jeannin P, Delneste $Y$, Lecoanet-Henchoz S, Gauchat JF, Ellis J, Bonnefoy JY: CD86 (B7-2) on human B cells. A functional role in proliferation and selective differentiation into IgE- and IgG4-producing cells. J Biol Chem 1997, 272:15613-15619.

44. Anatriello E, Ribeiro JM, de Miranda-Santos IK, Brandao LG, Anderson JM, Valenzuela JG, Maruyama SR, Silva JS, Ferreira BR: An insight into the sialotranscriptome of the brown dog tick, Rhipicephalus sanguineus. BMC Genomics 2010, 11:450.

45. Prates DB, Santos LD, Miranda JC, Souza AP, Palma MS, Barral-Netto M, Barral A: Changes in amounts of total salivary gland proteins of Lutzomyia longipallpis (Diptera: Psychodidae) according to age and diet. J Med Entomol 2008, 45:409-413.

46. Leboulle G, Rochez C, Louahed J, Ruti B, Brossard M, Bollen A, Godfroid E: Isolation of Ixodes ricinus salivary gland mRNA encoding factors induced during blood feeding. Am J Trop Med Hyg 2002, 66:225-233.

47. Testi R, D'Ambrosio D, De Maria R, Santoni A: The CD69 receptor: a multipurpose cell-surface trigger for hematopoietic cells. Immunol Today 1994, 15:479-483.

48. Sancho D, Gomez M, Sanchez-Madrid F: CD69 is an immunoregulatory molecule induced following activation. Trends Immunol 2005, 26:136-140.

49. Martin P, Gomez M, Lamana A, Matesanz Marin A, Cortes JR, RamirezHuesca M, Barreiro O, Lopez-Romero P, Gutierrez-Vazquez C, de la Fuente $\mathrm{H}$, et al: The leukocyte activation antigen CD69 limits allergic asthma and skin contact hypersensitivity. J Allergy Clin Immunol 2010, 126:355-365, 365 e351-353.

50. Zeidner NS, Dolan MC, Massung R, Piesman J, Fish D: Coinfection with Borrelia burgdorferi and the agent of human granulocytic ehrlichiosis suppresses IL-2 and IFN gamma production and promotes an IL-4 response in $\mathrm{C} 3 \mathrm{H} / \mathrm{HeJ}$ mice. Parasite Immunol 2000, 22:581-588.

51. Zeidner NS, Schneider BS, Rutherford JS, Dolan MC: Suppression of Th2 cytokines reduces tick-transmitted Borrelia burgdorferi load in mice. J Parasitol 2008, 94:767-769.

52. Goff WL, Johnson WC, Parish SM, Barrington GM, Tuo W, Valdez RA: The age-related immunity in cattle to Babesia bovis infection involves the rapid induction of interleukin-12, interferon-gamma and inducible nitric oxide synthase mRNA expression in the spleen. Parasite Immunol 2001, 23:463-471.

53. Goff WL, Johnson WC, Horn RH, Barrington GM, Knowles DP: The innate immune response in calves to Boophilus microplus tick transmitted Babesia bovis involves type-1 cytokine induction and NK-like cells in the spleen. Parasite Immunol 2003, 25:185-188.

54. Schneider DA, Yan H, Bastos RG, Johnson WC, Gavin PR, Allen AJ, Barrington GM, Herrmann-Hoesing LM, Knowles DP, Goff WL: Dynamics of bovine spleen cell populations during the acute response to Babesia bovis infection: an immunohistological study. Parasite Immunol 2010, 33:34-44.

55. Brown WC, Norimine J, Knowles DP, Goff WL: Immune control of Babesia bovis infection. Vet Parasitol 2006, 138:75-87.

56. Goff WL, Storset AK, Johnson WC, Brown WC: Bovine splenic NK cells synthesize IFN-gamma in response to IL-12-containing supernatants from Babesia bovis-exposed monocyte cultures. Parasite Immunol 2006, 28:221-228.

57. Wehner R, Dietze K, Bachmann M, Schmitz M: The bidirectional crosstalk between human dendritic cells and natural killer cells. J Innate Immun 2011, 3:258-263.

doi:10.1186/1756-3305-5-38

Cite this article as: Brake and Pérez de León: Immunoregulation of bovine macrophages by factors in the salivary glands of Rhipicephalus microplus. Parasites \& Vectors 2012 5:38.

\section{Submit your next manuscript to BioMed Central and take full advantage of:}

- Convenient online submission

- Thorough peer review

- No space constraints or color figure charges

- Immediate publication on acceptance

- Inclusion in PubMed, CAS, Scopus and Google Scholar

- Research which is freely available for redistribution

Submit your manuscript at www.biomedcentral.com/submit
Biomed Central 